Kivimäki Antti (Orcid ID: 0000-0003-0753-8164)

\title{
Negative-ion/positive-ion coincidence spectroscopy as a tool to identify anionic fragments: The case of core-excited $\mathrm{CHF}_{3}$
}

A. Kivimäki ${ }^{1,2}$, C. Stråhlman ${ }^{3,2}$, R. Sankari ${ }^{4,2}, \mathrm{R}$. Richter
${ }^{1}$ Nano and Molecular Systems Research Unit, University of Oulu, 90014 Oulu, Finland
${ }^{2}$ MAX IV Laboratory, Lund University, 22100 Lund, Sweden
${ }^{3}$ Department of Materials Science and Applied Mathematics, Malmö University, 20506
Malmö, Sweden
${ }^{4}$ Surface Science Group, Laboratory of Photonics, Physics Unit, Tampere University, P.O.
Box 692, 33014 Tampere, Finland
${ }^{5}$ Elettra-Sincrotrone Trieste, 34149 Trieste, Italy
Corresponding author: antti.kivimaki@ maxiv.lu.se
Abstract
We have studied the dissociation of the trifluoromethane molecule, CHF 3 , into negative ionic
fragments at the C 1s and F 1s edges. The measurements were performed by detecting
coincidences between negative and positive ions. We observed five different negative ions: $\mathrm{F}^{-}$
, $\mathrm{H}^{-}$, C-, CF-, and $\mathrm{F}_{2}^{-}$. Their production was confirmed by the analysis of triple coincidence
events (negative-ion/positive-ion/positive-ion or NIPIPI coincidences) that were recorded
with cleaner signals than those of the negative-ion/positive-ion coincidences. The intensities
of the most intense NIPIPI coincidence channels were recorded as a function of photon
energy across the C 1s and F 1s excitations and ionization thresholds. We also observed
dissociation channels involving the formation of one negative ion and three positive ions. Our
results demonstrate that negative-ion/positive-ion coincidence spectroscopy is a very
sensitive method to observe anions, which at inner-shell edges are up to three orders of
magnitude less probable dissociation products than cations.

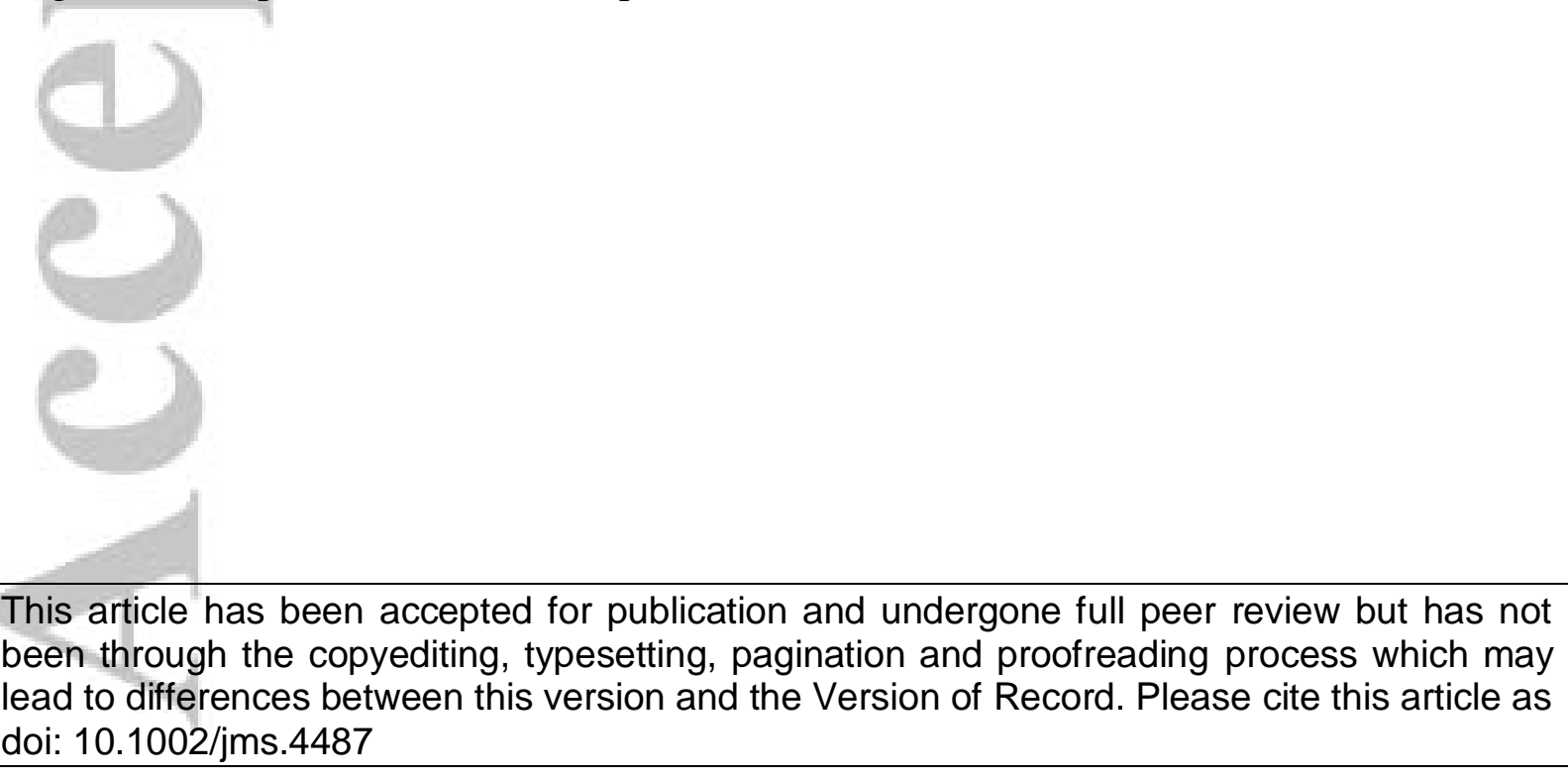

This article is protected by copyright. All rights reserved. 


\section{Introduction}

Processes involving the excitation and ionization of K-shell electrons of trifluoromethane $\left(\mathrm{CHF}_{3}\right)$, also known as fluoroform, have been studied surprisingly seldom, considering the molecule's small size and resemblance to $\mathrm{CF}_{4}$, a prototypical molecule of high symmetry (point group $\mathbf{T}_{\mathbf{d}}$ ). The $\mathrm{C} 1 \mathrm{~s}$ and $\mathrm{F} 1 \mathrm{~s}$ ionization energies $\mathbf{o f} \mathbf{C H F}_{\mathbf{3}}$ have been determined to be 299.14(3) eV (an adiabatic value) ${ }^{1}$ and $694.1 \mathrm{eV},{ }^{2}$ respectively. In the series of methane and fluorinated methanes, $\mathrm{CH}_{n} \mathrm{~F}_{4-\mathrm{n}}(\mathrm{n}=0-4)$, the $\mathrm{C} 1 \mathrm{~s}$ and $\mathrm{F} 1 \mathrm{~s}$ absorption features continuously shift toward higher energies when the number of fluorine atoms is increased. ${ }^{3,4}$ These shifts are caused by the high electronegativity of the fluorine atom. The replacement of hydrogens by fluorines results in the withdrawal of electron density from the central atom with a resulting increase in the binding energy of the inner-shell electrons. ${ }^{5}$ Based on electronegativity differences between the atoms making a bond, the $\mathrm{CHF}_{3}$ molecule can be classified as having three polar covalent $\mathrm{C}-\mathrm{F}$ bonds and a nonpolar covalent $\mathrm{C}-\mathrm{H}$ bond.

The carbon 1s photoabsorption spectrum of $\mathrm{CHF}_{3}$ is characterized by two overlapping broad features, which represent transitions to the empty valence orbitals $\sigma^{*} \mathrm{e}$ and $\sigma^{*} \mathrm{a}_{1}$, and by several considerably narrower peaks, which arise from transitions to atomic-like Rydberg orbitals. The $\mathrm{F} 1 \mathrm{~s}$ absorption spectrum of $\mathrm{CHF}_{3}$ only shows one distinct and wide feature, which has been assigned to the $\mathrm{F} 1 \mathrm{~s} \rightarrow \sigma^{*}$ transition. ${ }^{4}$ Ueda et al. ${ }^{4}$ also reported resonant and normal Auger electron spectra of $\mathrm{CHF}_{3}$ and $\mathrm{CH}_{3} \mathrm{~F}$ at selected core excitations and in the core ionization continuum. These spectra arise when the core-hole is filled by a valence electron and another valence electron is emitted (and its kinetic energy is measured), leading to singly charged final states in the case of resonant Auger decay and doubly charged final states in the case of normal Auger decay. Since the ground state of the $\mathrm{CHF}_{3}{ }^{+}$ion is not stable, ${ }^{6}$ the parent molecular ion produced in any kind of Auger processes dissociates immediately. Ion-mass spectrometry studies of $\mathrm{CHF}_{3}$ using low-energy electron impact ionization have revealed the cations $\mathrm{CF}_{n}^{+}(\mathrm{n}=1-3), \mathrm{CHF}_{\mathrm{n}}^{+}(\mathrm{n}=1,2), \mathrm{F}^{+}, \mathrm{C}^{+}$, and $\mathrm{H}^{+}$(e.g., $\left.{ }^{7}\right)$. To our knowledge, fragmentation of $\mathrm{CHF}_{3}$ following core excitation and core ionization has not been reported in the literature. However, such a study has been carried out for the resembling $\mathrm{CF}_{4}$ molecule, ${ }^{8}$ observing all possible singly charged cations (including $\mathbf{F}_{2}{ }^{+}$, which cannot be produced by a simple bond breakage), several dications $\left(\mathrm{C}^{2+}, \mathrm{F}^{2+}, \mathrm{CF}^{2+}, \mathrm{CF}_{2}{ }^{2+}\right.$ and $\left.\mathrm{CF}_{3}{ }^{2+}\right)$, and even negative ions $\left(\mathrm{C}^{-}, \mathrm{F}^{-}\right.$and $\left.\mathrm{CF}^{-}\right)$. The appearance of dications can be explained by Auger processes, where two or even three electrons are emitted simultaneously, or by Auger cascades, where the final states of the first-step Auger decay in the parent molecular ion are so highly excited that they decay further by second-step Auger decay, or by autoionization in excited singly charged fragments.

We have recently studied fragmentation channels involving negative ions at the core edges of water, formic acid and methanol. ${ }^{9-11}$ Our experimental setup consists of two time-of-flight (TOF) spectrometers; ${ }^{12}$ one is used to detect positive ions, the other negative ions. Electrons, which often interfere with negative ion detection, are deflected by a weak magnetic field that is created by permanent magnets, placed outside the vacuum chamber. The set-up has proven to be very sensitive when operated in a measurement mode where negative and positive ions are detected in coincidence. For instance, in methanol we observed $\mathrm{C}^{-}$and $\mathrm{CH}^{-}$fragments. ${ }^{11}$ 
These ions have not been detected in earlier partial ion yield measurements using a $180^{\circ}$ magnetic mass spectrometer. ${ }^{13}$ A further proof of the sensitivity of this technique is exemplified in our data recorded for methanol and formic acid. ${ }^{10,11}$ In this case, we detected coincidences between one negative ion and up to three positive ions. The relative intensities of the cations and anions can be appreciated from the study of Stolte et al. ${ }^{14}$ At the $\mathrm{O} 1 \mathrm{~s}$ edge of water, the intensities of $\mathrm{O}^{+}$and $\mathrm{H}^{+}$were found to be 2-3 orders of magnitude higher than those of the corresponding anions $\mathrm{O}^{-}$and $\mathrm{H}^{-}$.

The coincidence detection of negative and positive ions not only helps us to identify negative ions released by a given sample molecule, but also gives information on the dissociation channels that produce these anions. In the case of formic acid and methanol, we have found that the $\mathrm{CHOOH}^{+}$and $\mathrm{CH}_{3} \mathrm{OH}^{+}$parent ions, resulting from resonant Auger decay, can dissociate via a number (21 and 29 , respectively) of channels involving anions. ${ }^{10,11}$ The balance of charges dictates that if an anion is released in dissociation, the other fragments must carry a total charge of $+2 \mathrm{e}$ after resonant Auger decay and $+3 \mathrm{e}$ after normal Auger decay. Our studies so far have shown that singly charged cations are greatly favoured in molecular fragmentation processes involving anions. Negative-ion/dication coincidences are negligible in formic acid and methanol; ${ }^{10,11}$ however, $\mathrm{H}^{-} / \mathrm{O}^{2+}$ is a fairly important channel in water, ${ }^{9}$ perhaps due to the smaller number of atoms present in the molecule.

In the present paper, we extend our studies of negative-ion formation in core-excited molecules to $\mathrm{CHF}_{3}$. We anticipated that the high electronegativity of fluorine would translate into a particularly strong production of $\mathrm{F}^{-}$ions with respect to other anions. This indeed turned out to be true. We also expected to observe three other anions $\left(\mathrm{H}^{-}, \mathrm{C}^{-}\right.$, and $\mathrm{CF}^{-}$) and about twenty different NIPIPICO channels. The actual experiments revealed one more anion, $\mathrm{F}_{2}{ }^{-}$. In addition to negative-ion/positive-ion coincidence data, we report in this paper the partial positive ions yields of $\mathrm{CHF}_{3}$ at the $\mathrm{C} 1$ s edge.

\section{Experimental}

The experiments were performed at the Gas Phase Photoemission beamline ${ }^{15}$ of the Elettra synchrotron radiation facility. The beamline receives undulator radiation in the photon energy range 13.5-900 eV. Radiation is monochromatized using a spherical grating monochromator, equipped with five interchangeable gratings to guarantee a high $\left(\sim 10^{4}\right)$ resolving power in the whole operation range. The present experiments were carried out with a photon energy resolution of $\sim 40 \mathrm{meV}$ at the $\mathrm{C} 1 \mathrm{~s}$ edge and of $\sim 120 \mathrm{meV}$ at the $\mathrm{F} 1 \mathrm{~s}$ edge. The photon energy was calibrated at the $\mathrm{C} 1 \mathrm{~s}$ edge using the energies of the $\mathrm{C} 1 \mathrm{~s}$ excitations of the $\mathrm{CO}_{2}$ molecule ${ }^{16}$ and at the F 1s edge, approximately, using the energy scale given in Ref. 4.

$\mathrm{CHF}_{3}$ gas was directed into the experimental chamber through a hypodermic needle whose tip was carefully placed close to the monochromatized photon beam. The pressure in the experimental chamber was about $3 \cdot 10^{-7}$ mbar during the experiments, but the local pressure in the interaction region was estimated to be 10-50 times higher. Positive and negative ions resulting from the interaction of photons with sample molecules were extracted by the constant electric field of $\mathbf{2 9 0} \mathbf{V} / \mathbf{c m}$ towards the two TOF spectrometers. The limiting factor for the collection efficiency was the cut-off kinetic energy of $5.5 \mathrm{eV}$ for positive ions, ${ }^{10}$ faster cations with the momentum oriented perpendicularly to the TOF axis could escape the 
detection. The TOF spectrometers were mounted opposite one another and placed at the angle of $54.7^{\circ}$ with respect to the electric vector of the linearly polarized synchrotron radiation. This has the effect to minimize angular effects in the measured ion intensities. ${ }^{17}$ The contribution of electrons to the negative particle signal was minimized by placing small permanent magnets in suitable positions outside the vacuum chamber. The magnets were removed when positive ions were measured in coincidence with electrons.

In the NIPICO experiments we do not measure the flight times of negative ions directly, but rather establish the presence of anions from arrival time differences (ATDs) between negative and positive ions. In practice, an external pulse generator gives time stamps at a chosen frequency (typically $10 \mathrm{~Hz}$ ) and the arrival times of negative and positive ions occurring within a pre-selected time (we used $80 \mathrm{~ms}$ ) from these time stamps are written into a data file. The arrival times are analysed afterwards using a specifically written routine in the data analysis program Igor Pro. ${ }^{18}$ This arrangement allows for the possibility that a negative ion can arrive either before or after the positive ions, depending on their masses. The analysis can thus yield negative-ion/positive-ion coincidences (NIPICO), negative-ion/positiveion/positive-ion coincidences (NIPIPICO), and so on. For the photoelectron/positive-ion coincidence (PEPICO) measurements, which we employed to measure the partial positive ion yields, the wiring was changed so that electron signals were directly used as start signals and positive ion signals as stop signals (i.e., the pulse generator was not used).

\section{Results and discussion}

\subsection{Positive ions at the $\mathrm{C} K$ edge}

Even though the main focus of our study was on negative-ion formation, we begin by showing the total and partial ion yields of positive ions (Figure 1) recorded at the $\mathrm{C} 1 \mathrm{~s}$ edge because negative ions in our experiments were measured in coincidence with positive ions. For the assignment of negative-ion/positive-ion coincidence channels, it is important to know which positive ions are created upon core excitation. Note however that the relative intensity ratios of the positive ions detected in coincidence with negative ions may differ from those determined from the TOF spectra containing all positive ions.

The most intense positively charged fragments after $\mathrm{C} 1 \mathrm{~s}$ excitations were measured to be $\mathrm{F}^{+}$and $\mathrm{CF}^{+}$, followed by $\mathrm{H}^{+}$and $\mathrm{C}^{+}$. In reality, the yield of $\mathrm{H}^{+}$is higher because fast protons can escape detection. We cannot estimate this fraction without additional information about their kinetic energy distribution. The yields of these four fragments do not show large differences as a function of photon energy. However, a more careful inspection reveals that the production of $\mathrm{H}^{+}$appears slightly suppressed at the $\sigma^{*}$ excitations (294-296 eV) relative to the Rydberg excitations (296.8-299 eV), when their relative intensities are compared to the total ion yield (bottom right in Figure 1). The reduced intensity of $\mathrm{H}^{+}$at the $\sigma^{*}$ excitations could be explained, at least in principle, if $\mathrm{H}^{+}$ions received higher kinetic energies in dissociation processes at the $\sigma^{*}$ excitations than at the Rydberg excitations. Another and more likely possibility is that dissociation following $\mathrm{C} 1 \mathrm{~s}$ $\rightarrow \sigma^{*}$ excitations simply produces less $\mathrm{H}^{+}$ions because we do see variations in relative intensities between the resonances in the case of other fragments (see below), for which ions are not expected to escape detection because of their lower kinetic energies. 
When compared to the relative intensities in TIY, the production of $\mathrm{CH}^{+}$appears enhanced at the $\mathrm{C} 1 \mathrm{~s} \rightarrow \sigma^{*}$ resonances and particularly so at $\mathrm{C} 1 \mathrm{~s} \rightarrow \sigma^{*} \mathrm{a}_{1}$ resonance. A similar behaviour is visible in the $\mathrm{CHF}^{+}$yield. The production of $\mathrm{CF}_{3}{ }^{+}$is the most favoured at the $\mathrm{C} 1 \mathrm{~s} \rightarrow \sigma^{*} \mathrm{e}$ resonance, while it is very weak at the other valence resonance, $\mathrm{C} 1 \mathrm{~s} \rightarrow \sigma^{*} \mathrm{a}_{1}$. Thus there are clear differences in fragmentation pathways between the two $\mathrm{C} 1 \mathrm{~s} \rightarrow \sigma^{*}$ resonances. In addition, we observed the $\mathrm{F}_{2}{ }^{+}$ion in the sum of the TOF spectra, but its intensity is too low to be shown as a yield in Figure 1.

In order to assess the production of dications, we added the TOF spectra in the selected photon energy ranges, shown in the inset of Figure 2, and normalized them to the sum of the photodiode currents registered at each photon energy. The partial sums of the TOF spectra thus obtained are shown in the main panel of Figure 2. The bottom TOF spectrum was measured below the $C$ 1s $\rightarrow \sigma^{*}$ resonances and it represents our reference spectrum, even though it probably contains a small contribution due to the tails of the C $1 \mathrm{~s} \rightarrow \sigma^{*}$ resonances. The other partial sums depict the ion production in the different core excitation regions and just above the $C$ 1s ionization energy. We can clearly identify the enhanced production of $\mathrm{C}^{2+}$ and $\mathrm{CF}^{2+}$ at the $\mathrm{C} 1 \mathrm{~s}$ excitations and above the $\mathrm{C1s}$ threshold. The situation is less clear-cut for $\mathrm{F}^{2+}$, which shows no sharp peak. Nevertheless, we attribute the intensity increase around $\mathrm{m} / \mathrm{z}=9.5$ u to $\mathrm{F}^{2+}$ ions; the width of the feature can be explained by the high kinetic energies of the $\mathrm{F}^{2+}$ ions. The sharp peak at $\mathrm{m} / \mathrm{z}=16 \mathrm{u}$ deserves special attention. It could be caused by $\mathrm{O}^{+}$, resulting from the fragmentation of the rest gas molecules $\mathrm{O}_{2}$ or $\mathrm{H}_{2} \mathrm{O}$. However, the intensity of this peak resonates at the photon energies corresponding to the $\mathrm{C} 1 \mathrm{~s}$ excitations, whereas the intensity of $\mathrm{O}^{+}$originating from water or $\mathrm{O}_{2}$ would not do so. We therefore believe that the $\mathrm{m} / \mathrm{z}=16 \mathrm{u}$ peak is at least partly due to $\mathrm{CHF}^{2+}$. The $\mathrm{CHF}^{2+}$ dication may not have been observed before in photodissociation studies, but it has been produced in dissociative electron ionization of fluoromethane $\left(\mathrm{CH}_{3} \mathrm{~F}\right) .{ }^{19}$

We do not show the yields of $\mathrm{CF}^{2+}$ and $\mathrm{CHF}^{2+}$ in Figure 1 because their intensities cannot be extracted reliably. It is not clear where the background intensity in the $\mathrm{m} / \mathrm{z}$ range of 14.6-16.6 u comes from, but it may be caused by the $\mathrm{CF}^{2+}$ and $\mathrm{CHF}^{2+}$ ions themselves. Namely, the ions observed on tails can have higher kinetic energies than those observed in the central peak. In addition, $\mathrm{O}^{+}$probably makes some contribution to the intensity around $m / z=16 \mathrm{u} . \mathrm{CF}_{2}{ }^{2+}$ appears outside the $\mathrm{m} / \mathrm{z}$ range shown in Figure 2 . Its yield, shown in Figure 1, increases above the C 1s IP when normal Auger decay becomes the main decay channel of core-hole states. Finally, few $\mathbf{C F}_{3}{ }^{2+}$ ions were detected at the C1s-to-Rydberg excitations.

In summary, there are many photon energy dependent variations in the partial ion yields of positive ions. Studies of photoelectron/positive-ion/positive-ion coincidences (PEPIPICO) could explain some of these observations. PEPIPICO events were actually registered in the present measurements, but they were not our main interest at the time of the experiments and we used rather short measuring times (4 min for each spectrum). Furthermore, the present experimental setup is not the most suitable instrument for PEPIPICO spectroscopy, as fast electrons are not efficiently collected into the long TOF spectrometer. We therefore limit ourselves to mention a couple of observations regarding the $\mathrm{m} / \mathrm{z}=16 \mathrm{u}$ peak in Figure 2. We did not observe any $\mathrm{H}^{+} / \mathrm{O}^{+}$or $\mathrm{H}^{+} / \mathrm{OH}^{+}$ 
coincidences that normally signify the presence of water in the vacuum chamber. In contrast, we observed $\mathrm{H}^{+} / \mathrm{CF}^{+}$and $\mathrm{F}^{+} / \mathrm{CH}^{+}$coincidences that could be created if $\mathrm{CHF}^{2+}$ ions were formed in dissociative states.

The partial ion yields of positive ions were also measured at the F 1s edge. They are not reported here because they appear to display a structure that is due to an instrumental artefact.

\subsection{Identification of negative ions and NIPIPICO channels}

Figure 3 shows the arrival time difference spectra constructed by combining the data from several measurements across the $\mathrm{C} 1 \mathrm{~s} \rightarrow \sigma^{*} \mathrm{e}$ and $\sigma^{*} \mathrm{a}_{1}$ resonances (solid red curve) and at the $\mathrm{F} 1 \mathrm{~s} \rightarrow \sigma^{*}$ resonance (black dotted curve). The intensity scale refers to the former curve and it was obtained by binning the arrival time differences within $10 \mathrm{~ns}$ wide intervals. The dotted curve has been scaled to the same height at the $\mathrm{F}^{-} / \mathrm{H}^{+}$peak (leftmost in the spectrum). These measurements were performed using the same potentials in the TOF spectrometer as in the previous study on methanol. ${ }^{11}$ The flight times of the positive and negative ions therefore followed the equations derived in Ref. 11, allowing us to readily assign most peaks in Figure 3 and to calculate the expected positions of any conceivable NI/PI coincidence peaks. We have also indicated electron/positive-ion coincidence peaks, which arise due to the incomplete removal of electrons by the magnetic field. The positions of some peaks do not match any coincidences; they are labelled with question marks in Figure 3. It appears that some peak-like intensity originated from instrumental artefacts. For instance, no reasonable assignment can be proposed for the peak at $-2430 \mathrm{~ns}$ (on the right side of the $\mathrm{F}^{-} / \mathrm{H}^{+}$peak). On the other hand, this peak completely disappeared after undoing and redoing the electrical connections for the NIPICO measurements at the F 1s edge, suggesting that it was due to problems in connections.

NIPICO peaks that involve the $\mathrm{F}^{-}$ion are by far the most intense, especially when atomic cations $\mathrm{H}^{+}, \mathrm{C}^{+}$and $\mathrm{F}^{+}$are detected in coincidence. The relative intensities of these peaks change noticeably when the core excitation takes place in an $\mathrm{F}$ atom. In particular, $\mathrm{F}^{-} / \mathrm{F}^{+}$gains intensity upon going from the $\mathrm{C} 1 \mathrm{~s}$ edge to the $\mathrm{F} 1 \mathrm{~s}$ edge. At the $\mathrm{F} 1 \mathrm{~s}$ edge, the $\mathrm{F}^{-} / \mathrm{F}^{2+}$ coincidence also becomes visible. NIPICO peaks involving the $\mathrm{C}^{-}$and $\mathrm{H}^{-}$ions are about one order of magnitude weaker than those involving the $\mathrm{F}^{-}$ion. Qualitatively, the predominance of $\mathrm{F}^{-}$can be explained by two factors. First, it is energetically more favourable if a neutral fluorine atom rather than a carbon or hydrogen atom receives an extra electron: the electron affinity of $F(3.40 \mathrm{eV})$ is much higher than that of $\mathrm{C} \mathrm{or} \mathrm{H}(1.26$ and $0.75 \mathrm{eV}$, respectively). ${ }^{20}$ Second, since the $\mathrm{CHF}_{3}$ molecule contains three times more $\mathrm{F}$ atoms than $\mathrm{H}$ or $\mathrm{C}$ atoms, there are more chances for the formation of $\mathrm{F}^{-}$at the time of the molecular dissociation. One should also take into account that the liberation of a carbon atom from $\mathrm{CHF}_{3}$ requires the breaking of all the four molecular bonds, which may decrease the production of $\mathrm{C}^{-}$. Quantitative considerations of anion formation should be based on quantum chemical calculations on molecular dissociation after resonant and normal Auger decay. To our knowledge, such calculations have not been reported for anion formation in any molecules.

NI/PI peaks have most negative ATDs when a heavy negative ion is observed in coincidence with $\mathrm{H}^{+}$. The inset of Figure 3 shows that the expected ATDs of the $\mathrm{CF}^{-} / \mathrm{H}^{+}$and $\mathrm{F}_{2}-\mathrm{H}^{+}$ 
coincidences match very well with the positions of two narrow peaks in the experimental spectrum. This may not yet be a conclusive evidence for the detection of $\mathrm{CF}^{-}$and $\mathrm{F}_{2}^{-}$, as the same temporal region also shows some unknown peaks of larger intensity. However, the observation of both $\mathrm{CF}^{-}$and $\mathrm{F}_{2}^{-}$is confirmed by the NIPIPICO data of Figure 4, where these anions appear in coincidence with two positive ions. It is interesting to note the clear observation of $\mathrm{F}_{2}^{-} / \mathrm{H}^{+} / \mathrm{C}^{+}$, while the coincidence intensity in the circle corresponding to $\mathrm{F}_{2}^{-}$ $/ \mathrm{H}^{+} / \mathrm{F}^{+}$is not higher than in the other parts of the diagonal direction along which $\mathrm{NI} / \mathrm{H}^{+} / \mathrm{F}^{+}$ coincidences are aligned. Therefore, the observation of the $\mathrm{F}_{2}{ }^{-} / \mathrm{H}^{+} / \mathrm{F}^{+}$channel is not confirmed by our data. In Figure 4 (and in Figure 5 below), the thicker circles denote the expected positions of the observed NIPIPICO channels and the thinner circles show the expected positions of the unconfirmed NIPIPICO channels. (Some channels have no circles, but they are so intense that there is no doubt about their observation.) $\mathrm{CF}^{-}$and $\mathrm{F}_{2}^{-}$anions have previously been observed in the valence region of the $\mathrm{CF}_{3} \mathrm{Cl}, \mathrm{CF}_{3} \mathrm{Br}$ and $\mathrm{CF}_{3} \mathrm{I}$ molecules. ${ }^{21} \mathrm{CF}^{-}$was also observed at the core edges of $\mathrm{CF}_{4}$, but $\mathrm{F}_{2}{ }^{-}$was not. ${ }^{8}$

A wide-view NIPIPICO map is shown in Figure 5. In order to also make the weakest dissociation channels visible, in the analysis we have added all the data measured at different photon energies across the $\mathrm{F} 1 \mathrm{~s} \rightarrow \sigma^{*}$ resonance. This results in saturation in areas where the most intense NIPIPICO channels produce events; individual dots are no longer distinguishable and relative intensities of different channels cannot be appreciated. We will deal with the relative intensities of some NIPIPICO channels in the next subsection. In Figure 5 , coincidence islands arrange themselves in three different directions. In the vertical direction, the negative ion and the first positive ion remain the same, while the coincidence spots move up when the $\mathrm{m} / \mathrm{q}$ ratio of the second positive ion increases. This is most easily seen by looking at the $\mathrm{x}$-axis value near $-2500 \mathrm{~ns}$, which corresponds to the NI/PI 1 pair of $\mathrm{F}^{-}$ $/ \mathrm{H}^{+}$. In the horizontal direction, the negative ion and the second positive ion remain the same, while the spots move to right when the $\mathrm{m} / \mathrm{q}$ ratio of the first positive ion increases. Finally, the coincidence spots align diagonally, when the two positive ions remain the same and the mass of the negative ion changes (see, for example, $\mathrm{F}^{-} / \mathrm{H}^{+} / \mathrm{F}^{+}$and $\mathrm{C}^{-} / \mathrm{H}^{+} / \mathrm{F}^{+}$in the upper left corner of Figure 5).

The following NIPIPICO channels can be considered for $\mathrm{F}^{-}$and two singly charged

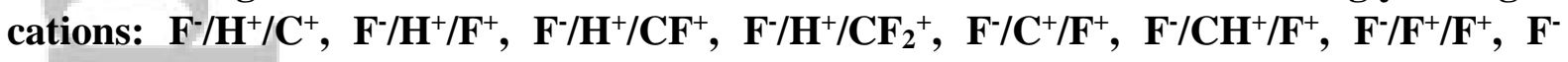
$/ \mathrm{F}^{+} / \mathrm{CF}^{+}$, and $\mathrm{F}^{-} / \mathrm{C}^{+} / \mathrm{CF}_{2}{ }^{+}$. (We exclude the weak $\mathrm{F}_{2}{ }^{+}$ion from considerations, as its appearance requires the formation of a new bond after dissociation.) We observe all these channels except for $\mathrm{F}^{-} / \mathrm{F}^{+} / \mathrm{CHF}^{+}$, and even for that channel there are hints of coincidences just above the $\mathrm{F}^{-} / \mathrm{F}^{+} / \mathrm{CF}^{+}$coincidence circle in the upper right corner of Figure 5. Outside the depicted area in Figure $5, \mathrm{~F}^{-} / \mathrm{H}^{+} / \mathrm{CF}_{2}{ }^{+}$is not observed at the $\mathrm{F} 1 \mathrm{~s}$ edge, but it appears weakly at the $\mathrm{C} 1 \mathrm{~s} \rightarrow \sigma^{*} \mathrm{e}$ and $\sigma^{*} \mathrm{a}_{1}$ resonances. That channel includes all the atoms of the parent molecule.

We have indicated with circles the expected positions of some weaker NIPIPI coincidence channels, including those where $\mathrm{C}^{2+}$ and $\mathrm{F}^{2+}$ are involved. It is still uncertain which NIPIPICO channels with dicationic participation are really observed in Figure 5, but $\mathrm{F}^{-}$ $/ \mathrm{C}^{2+} / \mathrm{F}^{+}$and $\mathrm{F}^{-} / \mathrm{H}^{+} / \mathrm{F}^{2+}$ are the strongest candidates. Among the encircled coincidence patterns we also find two more channels with the $\mathrm{F}_{2}^{-}$ion: $\mathrm{F}_{2}{ }^{-} / \mathrm{C}^{+} / \mathrm{F}^{+}$and $\mathrm{F}_{2}-\mathrm{CH}^{+} / \mathrm{F}^{+}$. The latter channel is the only "complete" channel within Figure 5; it includes all the atoms of the parent molecule. It is worth noting that we observed three of four possible NIPIPICO channels 
even for the-minority anion $F_{2}^{-}$(the unconfirmed channel is $F_{2}-/ H^{+} / F^{+}$, as discussed above). In Figure 5, we have also encircled the expected positions of the $\mathrm{F}^{-} / \mathrm{F}^{+} / \mathrm{F}^{+}$and $\mathbf{C F}^{-}$ $/ \mathrm{F}^{+} / \mathrm{F}^{+}$channels. They illustrate the cases where the MCP detector cannot register two $\mathrm{F}^{+}$ions if they arrive too close in time with respect to each other. Because of this instrumental limitation we are not certain about the observation of the $\mathbf{C F} / \mathbf{F}^{+} / \mathbf{F}^{+}$channel. The intensities of all dissociation channels with two $\mathrm{F}^{+}$ions are therefore underestimated in our experiments.

All NIPIPICO channels with $\mathrm{NI}=\mathrm{H}^{-}$are outside the area plotted in Figure 5. As can be expected from Figure 3, they are on average much weaker than the NIPIPICO channels with $\mathrm{NI}=\mathrm{F}^{-}$. We limit ourselves here to give the list of the observed $\mathrm{H}^{-}$channels: $\mathrm{H}^{-} / \mathrm{C}^{+} / \mathrm{F}^{+}, \mathrm{H}^{-}$ $/ \mathrm{F}^{+} / \mathrm{F}^{+}, \mathrm{H}^{-} / \mathrm{F}^{+} / \mathrm{CF}^{+}$and $\mathrm{H}^{-} / \mathrm{F}^{+} / \mathrm{CF}_{2}{ }^{+}$. The latter contains all the atoms of the parent molecule. No other NIPIPICO channels are possible if $\mathrm{NI}=\mathrm{H}^{-}$and $\mathrm{PIs}$ are limited to singly charged cations excluding $\mathrm{F}_{2}^{+}$. A NIPIPICO channel with the $\mathrm{C}^{-}$ion is visible in the upper part of Figure 5: $\mathrm{C}^{-} / \mathrm{H}^{+} / \mathrm{F}^{+}$. We also observed the only other possible channel involving $\mathrm{C}^{-}$and two singly charged positive ions, $\mathrm{C}^{-} / \mathrm{F}^{+} / \mathrm{F}^{+}$(not shown). (We again omit the $\mathrm{F}_{2}{ }^{+}$ion from considerations). Dications were not observed together with $\mathrm{H}^{-}$or $\mathrm{C}^{-}$.

\subsection{NIPIPICO yields}

Figure 6 shows the yields of the three most intense NIPIPICO channels involving $\mathrm{F}^{-}$as well as of the most intense non- $\mathrm{F}^{-}$NIPIPICO channel, $\mathrm{C}^{-} / \mathrm{H}^{+} / \mathrm{F}^{+}$, across the $\mathrm{C} 1 \mathrm{~s}$ excitations. They are compared to the total positive ion yield, which has been scaled to have approximately the same intensity as the $\mathrm{F}^{-} / \mathrm{H}^{+} / \mathrm{C}^{+}$and $\mathrm{F}^{-} / \mathrm{C}^{+} / \mathrm{F}^{+}$channels at the $\mathrm{C} 1 \mathrm{~s} \rightarrow \sigma^{*}$ e and $\sigma^{*} \mathrm{a}_{1}$ resonances. All the NIPIPICO channels shown become more intense at Rydberg excitations (like 3pe and 4pe) than at the valence resonances $\sigma^{*} \mathrm{e}$ and $\sigma^{*} \mathrm{a}_{1}$. The intensity increase at Rydberg excitations is larger for the $\mathrm{F}^{-} / \mathrm{C}^{+} / \mathrm{F}^{+}$channel than for the $\mathrm{F}^{-} / \mathrm{H}^{+} / \mathrm{C}^{+}$channel. We attribute the observation to the increased negative ion formation at the $\mathrm{C} 1 \mathrm{~s} \rightarrow$ Rydberg excitations. In fact, anion formation in valence photoexcitation of small molecules is generally associated with Rydberg resonances. ${ }^{21}$ In the case of core-excited states, spectator Auger decay is the most important decay channel in small molecules composed of light atoms. It conserves the Rydberg or valence character of the orbital to which the electron was promoted in the initial excitation process. Thus, (valence) ${ }^{-2} \operatorname{Ryd}^{1}$ type of states are produced at core-to-Rydberg resonances and (valence) ${ }^{-2}$ virt $^{1}$ states are populated at core-to-virtual valence excitations; here "valence" denotes any occupied valence orbitals, and Ryd and virt are respectively Rydberg and virtual valence orbitals that are unoccupied in the molecular ground state. The enhanced intensity of the NIPIPICO yields at $\mathrm{C}$ 1s-to-Rydberg excitations of $\mathrm{CHF}_{3}$ can therefore be understood, if the Rydberg character plays a similar role in the singly ionized final states of spectator Auger decay as it does in neutral valence-excited states. The enhanced intensity could also be explained, at least in principle, if positive ions had considerably smaller kinetic energies at the Rydberg excitations than at the valence resonances.

Figure 7 shows the same NIPIPICO yields at the F 1s edge together with the total positive ion yield (TPIY) measured simultaneously. The latter only displays one feature, which has been assigned to the $\mathrm{F} 1 \mathrm{~s} \rightarrow \sigma^{*}$ resonance. ${ }^{4}$ The NIPIPICO yields seem to peak at higher energies than the TPIY. The intensity order of the different NIPIPICO channels is the same at the F $1 \mathrm{~s}$ 
edge as at the $\mathrm{C} 1 \mathrm{~s}$ edge. The shape of the TPIY indicates that there are unresolved excitations between the $\mathrm{F} 1 \mathrm{~s} \rightarrow \sigma^{*}$ resonance and the $\mathrm{F} 1 \mathrm{~s}$ ionization potential. It is reasonable to assume that they have at least partial Rydberg character because that is where Rydberg resonances are located. The Rydberg character of the unresolved $F$ 1s excitations can explain the observed energy shifts of the NIPIPICO yields, if it increases negative ion formation in the same way as it does at the $\mathrm{C} 1 \mathrm{~s}$ edge.

\subsection{NIPIPIPI coincidences}

In order to check whether we can observe four-ion coincidences (one negative ion, three positive ions) we performed the analysis on the data set comprising measurements done at different photon energies across the $\mathrm{C} 1 \mathrm{~s} \rightarrow \sigma^{*} \mathrm{e}$ and $\sigma^{*} \mathrm{a}_{1}$ resonances and at the $\mathrm{F} 1 \mathrm{~s} \rightarrow \sigma^{*}$ resonance. Figures 8 and 9 show the results of the analysis that only used events where four particles had been observed within a short time interval. The main panel shows the arrival time difference (ATD) spectrum of the first positive ion with respect to the negative ion. We can observe that the $\mathrm{F}^{-} / \mathrm{H}^{+}$ion pair is the most likely combination and we have performed a further analysis for that peak. (Referring to Figure 2, the peaks at -900 ns and -400 ns correspond to $\mathrm{F}^{-} / \mathrm{C}^{+}$and $\mathrm{F}^{-} / \mathrm{F}^{+}$ion pairs, respectively, in Figures 8 and 9.) The insets thus show the $\mathrm{PI}_{2} / \mathrm{PI}_{3}$ coincidences only in the case where NI/PI have been restricted to be $\mathrm{F}^{-} / \mathrm{H}^{+}$. The $\mathrm{F}^{-} / \mathrm{H}^{+} / \mathrm{C}^{+} / \mathrm{F}^{+}$channel is observed to be a strong NIPIPIPICO channel. Its relative intensity with respect to the $\mathrm{F}^{-} / \mathrm{H}^{+} / \mathrm{F}^{+} / \mathrm{F}^{+}$channel could not be determined because in the latter case many events may have escaped registration due to the dead time of the detector. We also observe few events in the $\mathrm{F}^{-} / \mathrm{H}^{+} / \mathrm{F}^{+} / \mathrm{CF}^{+}$channel, where all constituent atoms of the parent molecule are included.

Figure 9 shows more $\mathrm{F}^{-} / \mathrm{H}^{+} / \mathrm{F}^{+} / \mathrm{F}^{+}$coincidences than Figure 8 . One can expect that the kinetic energy release in dissociation is higher at the $F$ 1s edge than at the $C 1$ s edge because the core-hole states are more highly excited, which can also lead to a higher total charge of the fragments. Two $\mathrm{F}^{+}$ions are ejected in different, perhaps almost opposite directions because of Coulombic repulsion. If the kinetic energy of the $\mathrm{F}^{+}$ions increases, the arrival time difference on the detector of the two $\mathrm{F}^{+}$ions originating from the same molecule will also increase. More of these ATDs become larger than the dead time of the MCP detector, resulting in the increased detection of $\mathrm{F}^{+} / \mathrm{F}^{+}$pairs.

Similar analysis of the NI/PI 1 peak around $-1000 \mathrm{~ns}\left(\mathrm{~F}^{-} / \mathrm{C}^{+}\right)$in the main panel of Fig. 8 only shows $\mathrm{F}^{-} / \mathrm{C}^{+} / \mathrm{F}^{+} / \mathrm{F}^{+}$coincidences, a large fraction of which could have been lost due to the dead time of the MCP detector.

\section{Conclusions}

We have studied the dissociation of the $\mathrm{CHF}_{3}$ molecule into positively and negatively charged fragments following K-shell photoexcitation and photoionization. The negativeion/positive-ion coincidence (NIPICO) technique implemented in this work can distinguish very weak dissociation channels. It is therefore well suited to determine which anionic species are present among the dissociation products. We found five anionic fragments: $\mathrm{F}^{-}, \mathrm{H}^{-}$, $\mathrm{C}^{-}, \mathrm{CF}^{-}$and $\mathrm{F}_{2}^{-}$, among which $\mathrm{F}^{-}$is by far the most probable. $\mathrm{CF}^{-}$and $\mathrm{F}_{2}^{-}$have very low 
intensities (about $1 \%$ of $\mathrm{F}^{-}$, if estimated from the intensity ratios between the $\mathrm{H}^{+} / \mathrm{F}^{-}$, $\mathrm{H}^{+} / \mathrm{CF}^{-}$and $\mathrm{H}^{+} / \mathrm{F}_{2}^{-}$coincidences).

Coincidence detection of a negative ion with two positive ions (i.e., NIPIPICO or negativeion/positive-ion/positive-ion coincidences) confirmed the appearance of the $\mathrm{CF}^{-}$and $\mathrm{F}_{2}^{-}$ions. The observed NIPIPICO channels - about 20 in total - comprise almost all possible combinations of a negative ion and two singly charged positive ions. For instance, we observed eight out of nine and three out of four such channels for $\mathrm{NI}=\mathrm{F}^{-}$and $\mathrm{F}_{2}^{-}$, respectively. The two NIPIPICO channels with the participation of dications $\left(\mathrm{C}^{2+}\right.$ or $\mathbf{F}^{2+}$ ) are of very low intensity. The intensities of four chosen NIPIPICO channels were followed as a function of photon energy across the $\mathrm{C} 1 \mathrm{~s}$ and $\mathrm{F} 1 \mathrm{~s}$ resonances and ionization potentials. Negative ion production was found to be slightly more probable at the $\mathbf{C}$ 1s-toRydberg resonances than at the $\mathrm{C} 1 \mathrm{1}$-to-valence resonances. At the $\mathrm{F}$ 1s edge, the shifted maxima of the NIPIPICO yields hint at the contribution of unresolved $F$ 1s excitations with Rydberg character in the energy region between the $\mathbf{F} 1 \mathrm{~s} \rightarrow \sigma^{*}$ resonance and the F 1s ionization potential. Summing up all recorded data - irrespective of photon energy at a given core edge - gave evidence of dissociation channels involving one negative ion and three positive ions (NIPIPIPICO channels). As a by-product of this study, we also reported the yields of many positive ions across the $\mathrm{C} 1 \mathrm{~s}$ edge of $\mathrm{CHF}_{3}$. The measured PEPICO spectra showed evidence of the rare $\mathrm{CHF}^{2+}$ ion.

\section{Acknowledgements}

The authors acknowledge Elettra-Sincrotrone Trieste for providing beamtime (Proposal No. 20150229) and the staff at Elettra for their kind assistance during the experiments. We are grateful to Dr. Noelle Walsh for careful reading of the manuscript.

\section{References}

[1] Myrseth V, Bozek JD, Kukk E, Sæthre LJ, Thomas TD. Adiabatic and vertical carbon 1s ionization energies in representative small molecules. J. Electron Spectrosc. Relat. Phenom. $2002,122,57$.

[2] Thomas TD. X-ray photoelectron spectroscopy of simple hydrocarbons. J. Chem. Phys. 1970, 52, 1373.

[3] Brown FC, Bachrach RZ, Bianconi A. Fine structure above the carbon K-edge in methane and in the fluoromethanes. Chem. Phys. Lett. 1978, 54, 425.

[4] Ueda K, Shimizu Y, Chiba H, Okunishi M, Ohmori K, Sato Y, Shigemasa E, Kosugi N. C 1s and $\mathrm{F}$ 1s photoabsorption and subsequent electronic decay of $\mathrm{CH}_{4}, \mathrm{CH}_{3} \mathrm{~F}, \mathrm{CH}_{2} \mathrm{~F}_{2}, \mathrm{CHF}_{3}$, and $\mathrm{CF}_{4}$. J. Electron Spectrosc. Relat. Phenom. 1996, 79, 441.

[5] Thomas TD. X-ray photoelectron spectroscopy of halomethanes. J. Am. Chem. Soc. 1970, 92, 4184.

[6] McKoy BV, as cited in Jiao CQ, Nagpal R, Haaland PD. Ion chemistry in trifluoromethane, $\mathrm{CHF}_{3}$. Chem. Phys. Lett. 1997, 269,117.

[7] Iga I, Sanches IP, Srivastava SK, Mangan M. Electron impact ionization of $\mathrm{CHF}_{3}$. Int. J. Mass Spectrom. 2001, 208, 159. 
[8] Guillemin R, Stolte WC, Piancastelli MN, Lindle DW. Jahn-Teller coupling and fragmentation after core-shell excitation in $\mathrm{CF}_{4}$ investigated by partial-ion-yield spectroscopy. Phys. Rev. A. 2010, 82, 043427.

[9] Stråhlman C, Kivimäki A, Richter R, Sankari R. Negative-ion/positive-ion coincidence yields of core-excited water. J. Phys. Chem A. 2016, 120, 6389.

[10] Stråhlman C, Kivimäki A, Richter R, Sankari R. Negative- and positive-ion fragmentation of core-excited formic-acid molecules studied with three- and four-ion coincidence spectroscopy. Phys. Rev. A. 2017, 96, 023409.

[11] Kivimäki A, Stråhlman C, Richter R, Sankari R. Fragmentation of methanol molecules after core excitation and core ionization studied by negative-ion/positive-ion coincidence experiments. J. Phys. Chem A. 2018, 122, 224.

[12] Stråhlman C, Sankari R, Kivimäki A, Richter R, Coreno M, Nyholm R. A tandem timeof-flight spectrometer for negative-ion/positive-ion coincidence measurements with soft x-ray excitation. Rev. Sci. Instrum. 2016, 87, 013109.

[13] Stolte WC, Öhrwall G, Sant'Anna MM, Dominguez Lopez I, Dang LTN, Piancastelli $\mathrm{MN}$, Lindle DW. $100 \%$ site-selective fragmentation in core-hole-photoexcited methanol by anion-yield spectroscopy. J. Phys. B. 2002, 35, L253.

[14] Stolte WC, Sant'Anna MM, Öhrwall G, Dominguez-Lopez I, Piancastelli MN, Lindle DW. Photofragmentation dynamics of core-excited water by anion-yield spectroscopy. Phys. Rev. A. 2003, 68, 022701.

[15] Prince KC, Blyth RR, Delaunay R, et al. The Gas-Phase Photoemission beamline at Elettra. J. Synchrotron Radiat. 1998, 5, 565.

[16] Prince KC, Avaldi L, Coreno M, Camilloni R, de Simone M. Vibrational structure of core to Rydberg excitations of carbon dioxide and dinitrogen oxide. J. Phys. B. 1999, 32, 2551.

[17] Morin P, Nenner I, Guyion PM, Dutuit O, Ito K. Time of flight photoelectron spectroscopy using synchrotron radiation study of resonances in $\mathrm{O}_{2}$. J. Chim. Phys. 1980, 77, 605.

[18] https://www.wavemetrics.com/

[19] Roithová J, Herman Z, Schröder D, Schwarz H. Competition of proton and electron transfers in gas-phase reactions of hydrogen-containing dications $\mathrm{CHX}^{2+}(\mathrm{X}=\mathrm{F}, \mathrm{Cl}, \mathrm{Br}, \mathrm{I})$ with atoms, nonpolar and polar molecules. Chem. Eur. J. 2006, 12, 2465.

[20] Kendall RA, Dunning TH, Harrison RJ. Electron affinities of the first-row atoms revisited. Systematic basis sets and wave functions. J. Chem. Phys. 1992, 96, 6796.

[21] Simpson MJ, Tuckett RP. Vacuum-UV negative photoion spectroscopy of gas-phase polyatomic molecules. Int. Rev. Phys. Chem. 2011, 30, 197.

This article is protected by copyright. All rights reserved. 


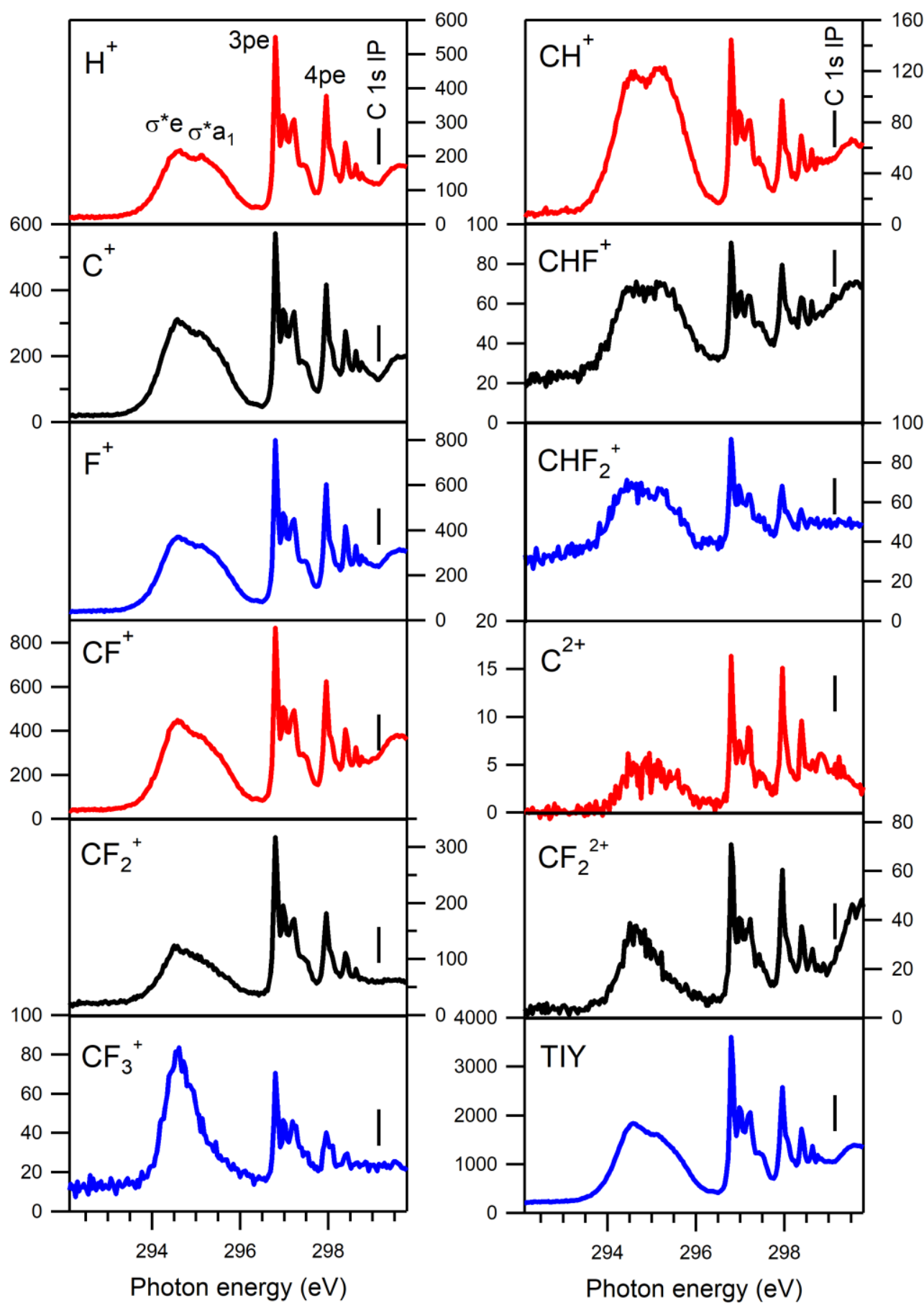

Figure 1. The partial ion yields of positive ions at the $\mathrm{C}$ 1s edge. They have been normalized to the photodiode current measured simultaneously. TIY shows the sum of the observed partial ion yields. The main resonances are labeled according to Ref. 4 in the top left panel. 


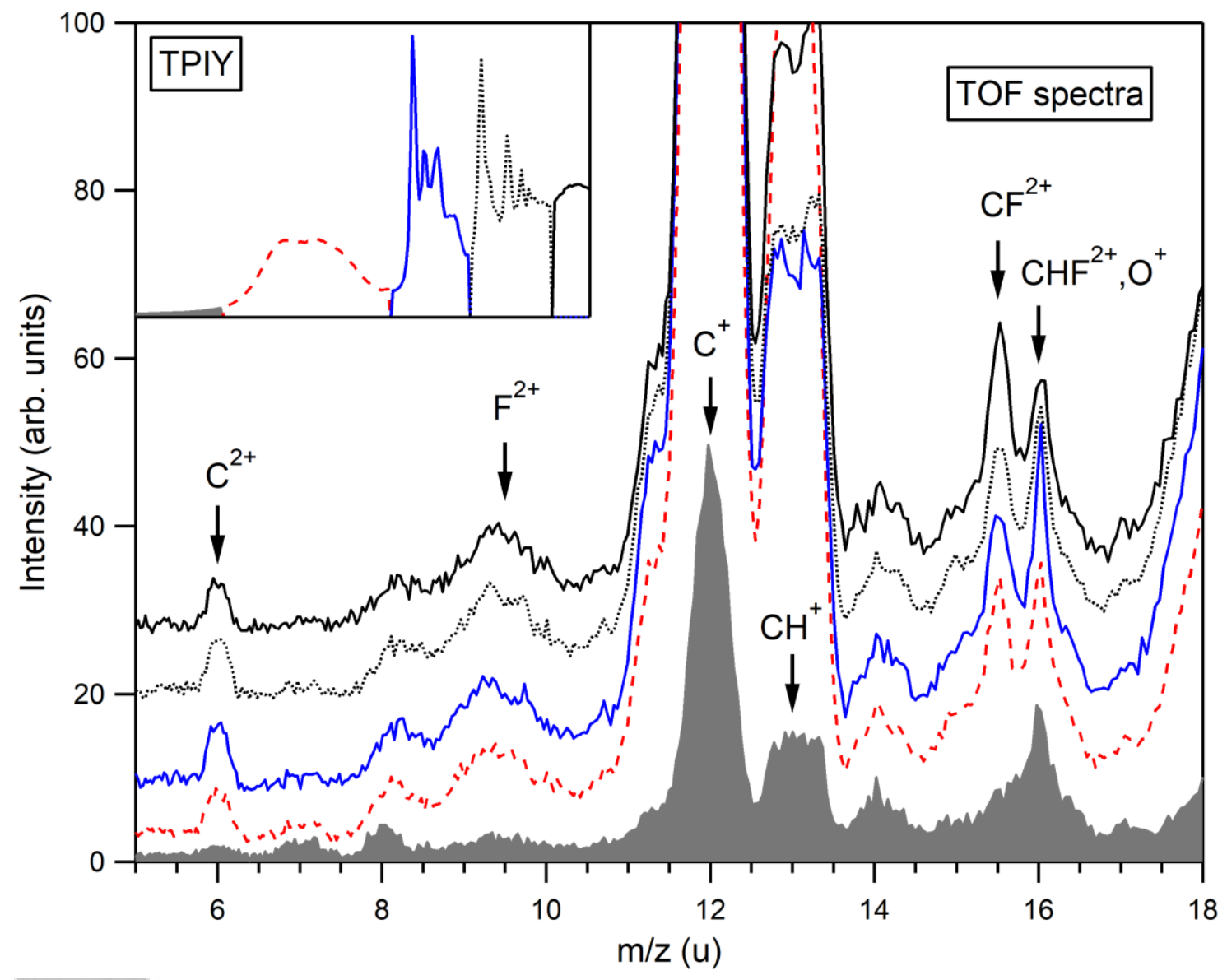

Figure 2. Normalized TOF spectra obtained by summing the measurements across the different photon energy ranges, indicated on the total positive ion yield (TPIY) in the inset. See Figure 1 for the energy values of the $\mathrm{x}$-axis in the inset. Similar curve types are used for the respective TOF spectra and the photon energy ranges. The main ions are labelled and their central positions are indicated with arrows. The TOF spectra are shifted vertically for clarity. 


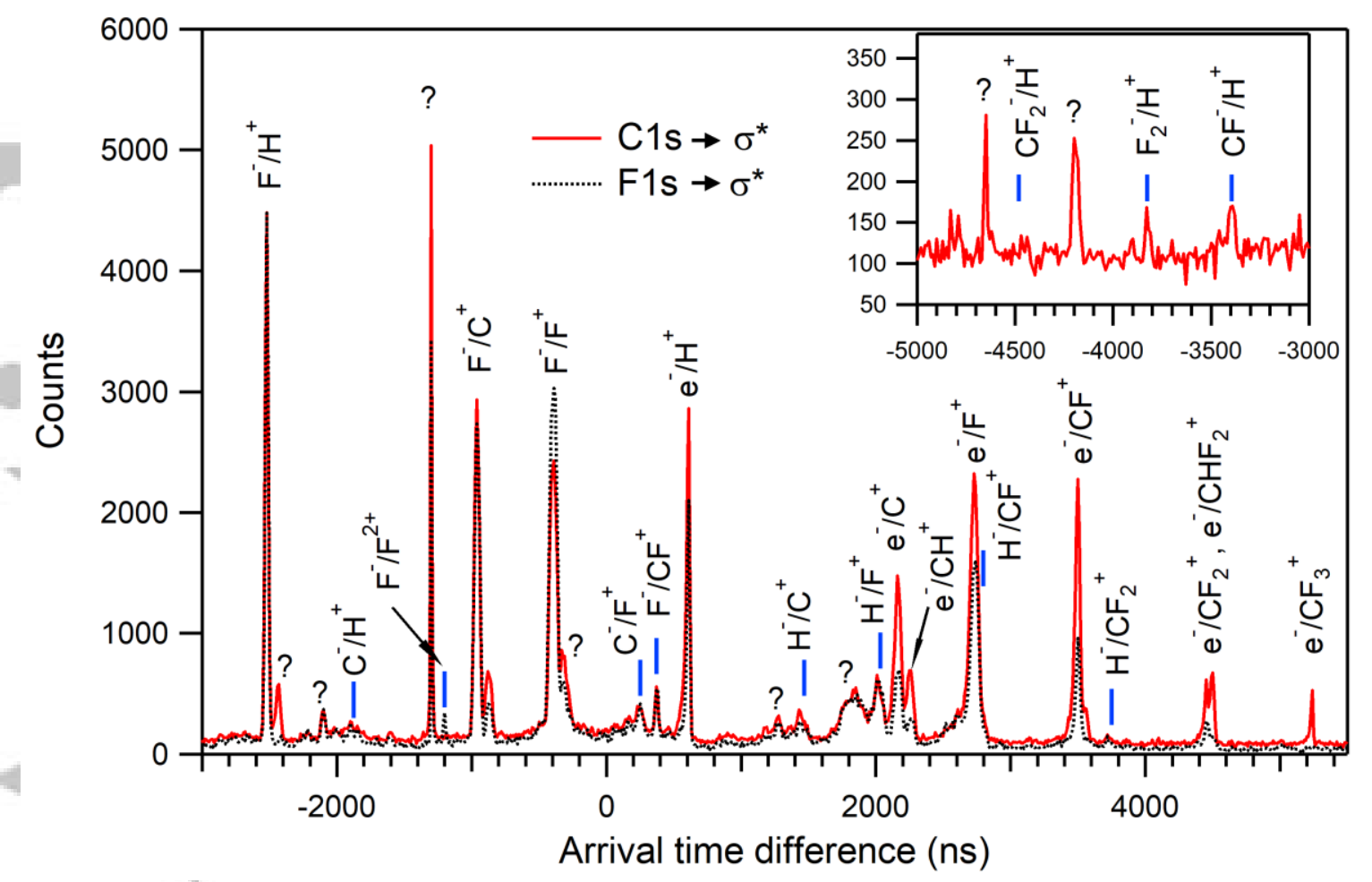

Figure 3. The arrival time difference spectra of $\mathrm{CHF}_{3}$ constructed from the measurements performed across the $\mathrm{C} 1 \mathrm{~s} \rightarrow \sigma^{*} \mathrm{e}$ and $\sigma^{*} \mathrm{a}_{1}$ resonances (solid curve) and across the $\mathrm{F} 1 \mathrm{~s} \rightarrow$ $\sigma^{*}$ resonance (dotted curve). Blue vertical bars show the expected positions of the indicated NI/PI coincidences. The total measuring time was $6 \mathrm{~h}$ for the solid curve and $4 \mathrm{~h}$ for the dotted curve. 




Figure 4. An extract of the NIPIPI coincidence map formed from the data taken across the C $1 \mathrm{~s} \rightarrow \sigma^{*} \mathrm{e}$ and $\sigma^{*} \mathrm{a}_{1}$ resonances, showing that part where coincidences with $\mathrm{NI}=\mathrm{F}_{2}^{-}$and $\mathrm{CF}^{-}$ are expected. The thicker and lighter (thinner black) circles with radius of $50 \mathrm{~ns}$ show the expected positions of the labelled observed (unconfirmed) NIPIPI coincidences. The measuring time was $6 \mathrm{~h}$. 




Figure 5. NIPIPICO map formed from the measurements across the $\mathrm{F} 1 \mathrm{~s} \rightarrow \sigma^{*}$ resonance. The thicker and lighter (thinner black) circles with radius of $50 \mathrm{~ns}$ show the expected positions of the labelled observed (unconfirmed) NIPIPI coincidences. 


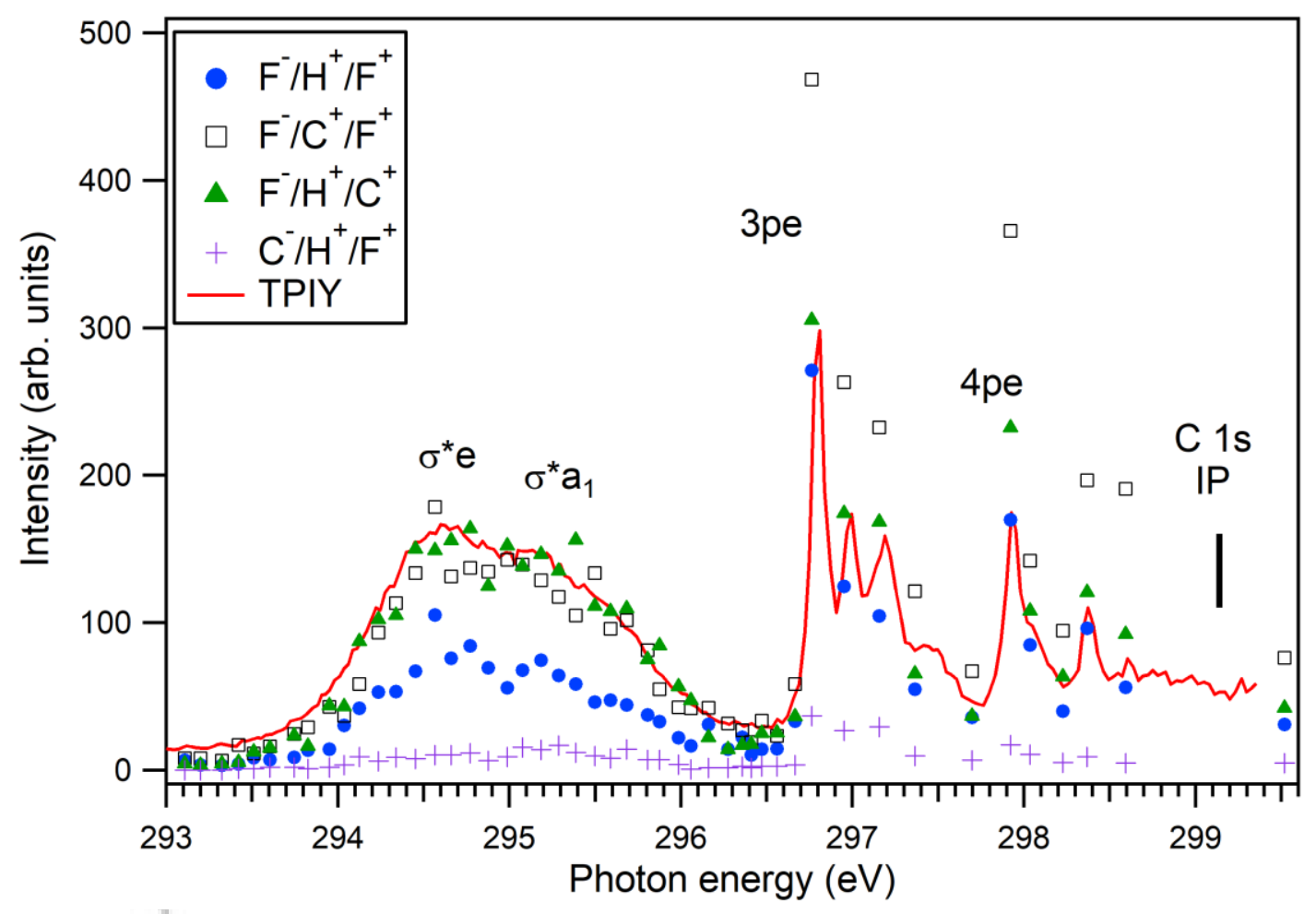

Figure 6. Selected NIPIPI coincidence yields at the $\mathrm{C} 1 \mathrm{~s}$ edge in comparison with the total positive ion yield (TPIY). The assignments of the resonances are from Ueda et al. ${ }^{4}$ Negative ion formation is more probable at the Rydberg excitations than at the $\sigma^{*}$ resonances. 


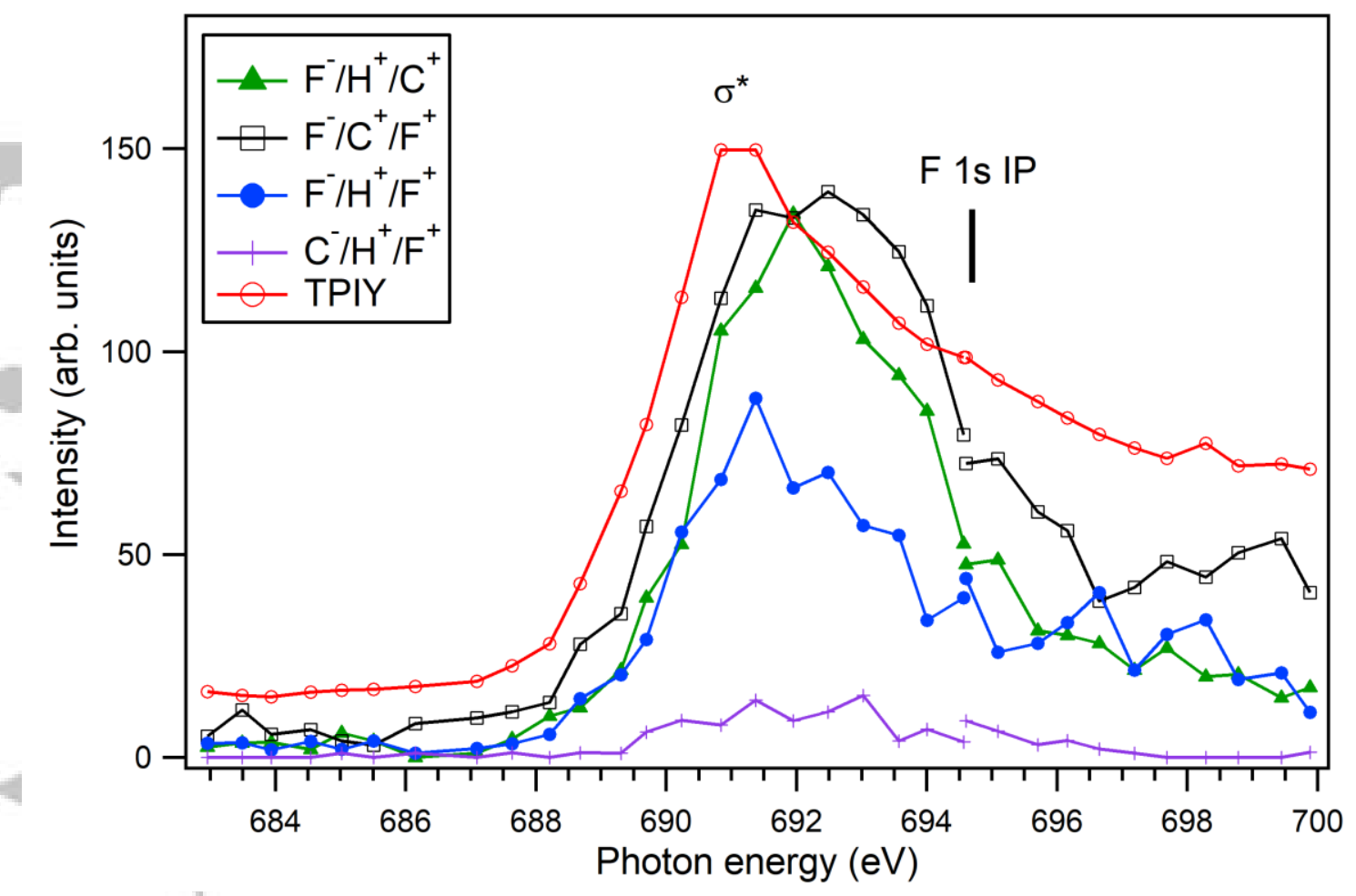

Figure 7. Selected NIPIPI coincidence yields at the F 1s edge in comparison with the total positive ion yield (TPIY) measured simultaneously. The assignment and approximate energy calibration are from Ref. 4. 


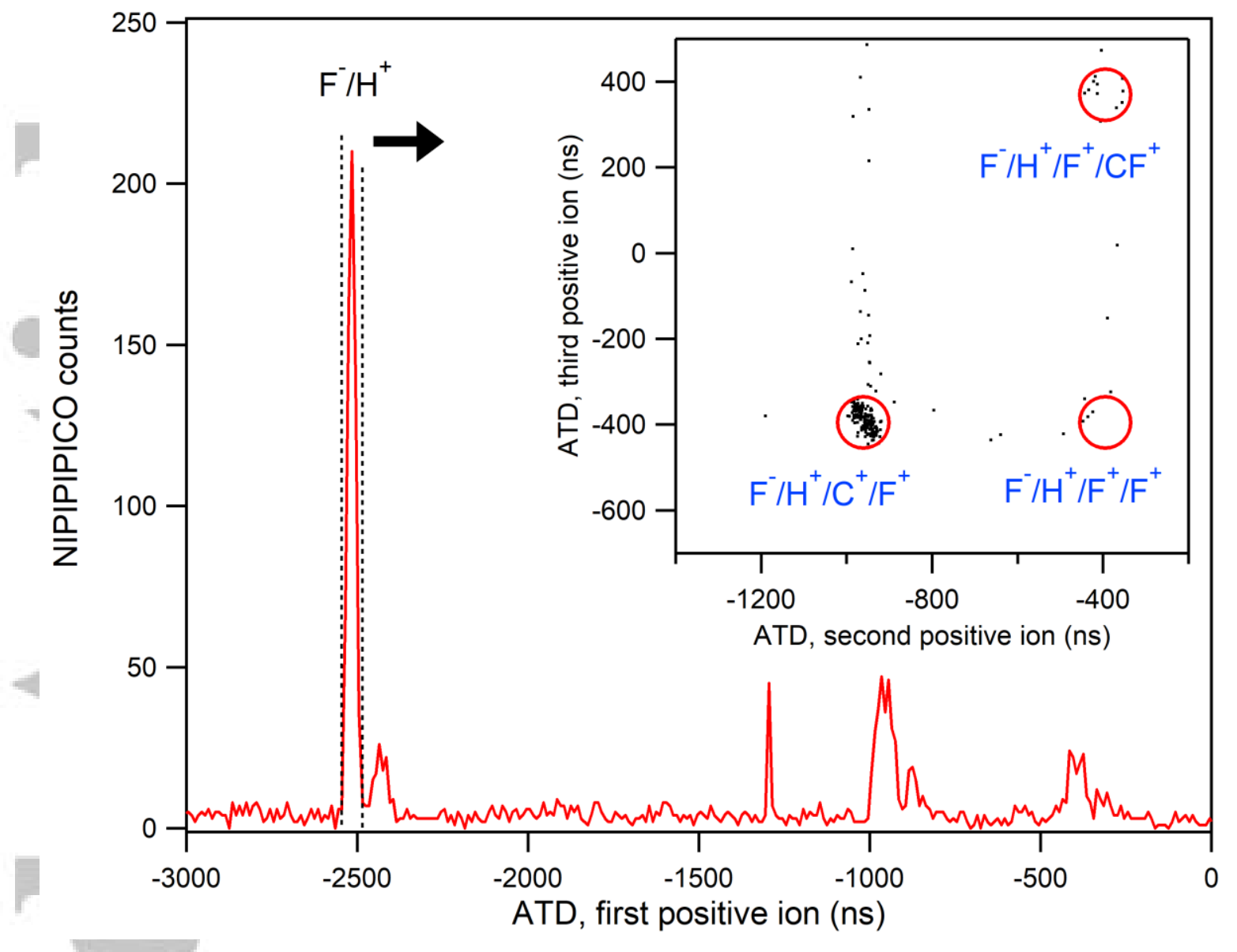

Figure 8. NIPIPIPICO spectrum at the $\mathrm{C} 1 \mathrm{~s} \rightarrow \sigma^{*} \mathrm{e}$ and $\sigma^{*} \mathrm{a}_{1}$ resonances $(6 \mathrm{~h}$ measuring time). The main panel shows the arrival time difference (ATD) spectrum of the first positive ion extracted from the events where one negative ion and three positive ions were detected in coincidence. The inset shows the ATD of the third positive ion $\left(\mathrm{PI}_{3}\right)$ vs that of the second positive ion $\left(\mathrm{PI}_{2}\right)$ among those $\mathrm{NIPI}_{1} \mathrm{PI}_{2} \mathrm{PI}_{3}$ events where NI/PI $I_{1}$ has been preselected to be $\mathrm{F}^{-}$ $/ \mathrm{H}^{+}$(the peak between the dotted vertical lines in the main panel). The circles show the expected positions of $\mathrm{PI}_{2} / \mathrm{PI}_{3}$ coincidences within the radius of $60 \mathrm{~ns}$. 


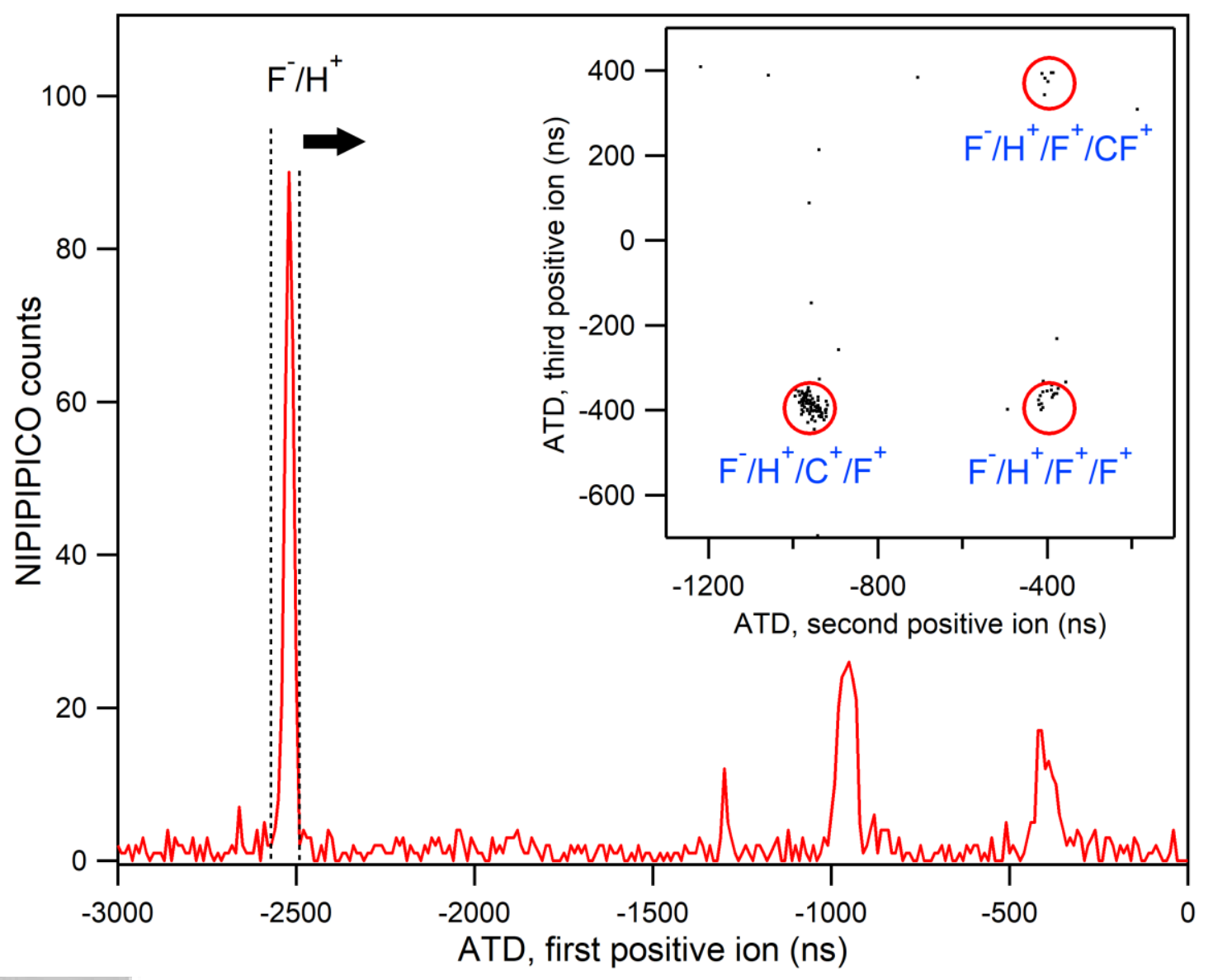

Figure 9. NIPIPIPICO spectrum measured across the $\mathrm{F} 1 \mathrm{~s} \rightarrow \sigma^{*}$ resonance $(4 \mathrm{~h}$ measuring time). See Figure 8 caption for details of the analysis. 